\title{
GLOBAL MENTAL HEALTH AND SYSTEMS OF DIAGNOSTIC CLASSIFICATION: CLINICAL AND CULTURAL PERSPECTIVES
}

\begin{abstract}
Renato D. Alarcón ${ }^{1}$
Abstract: Historical and conceptual aspects of Global Health and Global Mental Health are examined and topics such as resources, professional and social attitudes toward mental disorders, the multidimensional experience of getting ill and the presence of world systems of psychiatric diagnosis and classification, are reviewed. The application of these areas of knowledge in medical practice require the integrated use of clinical and socio-cultural perspectives whose precise alignment is an essential component of accurate diagnoses, successful treatments and a consistent improvement of mental health as a component of public health. The latter includes preventive measures applicable to general populations, communities and health care proper. Management of socio-cultural aspects of diagnosis and treatment is imperative as is that of the growing relationship between mental health and neurosciences. The operationalization of this series of interactive processes must be part of legislations which, in turn, can make training, research and dissemination of the resulting data, possible.
\end{abstract}

Key words: Global Health, Global Mental Health, psychiatric diagnosis, Integrated Health Care.

Salud Mental Global y sistemas de clasificación diagnóstica: perspectivas clínicas y culturales

Resumen: Se examinan aspectos históricos y conceptuales de Salud Global y Salud Mental Global, formulándose temas de revision sobre recursos, actitudes profesionales y sociales o colectivas en torno a la enfermedad mental, las varias dimensiones de la experiencia de enfermar y la vigencia de sistemas diagnósticos y de clasificación psiquiátrica a nivel mundial. Las aplicaciones de estas áreas de conocimiento en la práctica médica requieren el uso integrado de perspectivas clínicas y socio-culturales cuyo alineamiento preciso es componente esencial de un diagnóstico acertado, un tratamiento exitoso y una mejoría consistente de la salud mental como componente de la salud pública. Esta última incluye medidas preventivas aplicables en niveles de población general, comunitario y de atención en salud propiamente tal. El manejo de aspectos socio-culturales de diagnóstico y tratamiento es imperativo, al igual que el de la creciente relación entre salud mental y neurociencias. La operacionalización de estos procesos interactivos debe ser materia de legislaciones que posibiliten, a su vez, programas de adiestramiento profesional, investigación y difusión adecuada de la información resultante.

Palabras clave: Salud Global, Salud Mental Global, diagnóstico psiquiátrico, atención médica integrada

Saúde Mental Global e sistemas de classificação diagnóstica: perspectivas clínicas e culturais

Resumo: São examinados aspectos históricos e conceituais de Saúde Global e Saúde Mental Global, formulando-se temas de revisão sobre recursos, atitudes profissionais e sociais ou coletivas em torno da enfermidade mental, as várias dimensôes da experiência de enfermar e a vigência de sistemas diagnósticos e de classificação psiquiátrica em nível mundial. As aplicações destas áreas de conhecimento na prática médica requerem o uso integrado de perspectivas clínicas e socioculturais cujo alinhamento preciso é componente essencial de um diagnóstico acertado, um tratamento exitoso e uma melhoria consistente da saúde mental como componente da saúde pública. Esta última inclui medidas preventivas aplicáveis em níveis de população geral, comunitário e de atenção em saúde propriamente dita. O manejo de aspectos socioculturais de diagnóstico e tratamento é imperativo, igual ao da crescente relação entre saúde mental e neurociências. A operacionalização destes processos interativos deve ser matéria de legislaçóes que possibilitem, por sua vez, programas de adestramento profissional, pesquisa e difusão adequada da informação resultante.

Palavras-chave: Saúde Global, Saúde Mental Global, diagnóstico psiquiátrico, atenção médica integrada

\footnotetext{
${ }^{1}$ Emeritus Professor of Psychiatry, Mayo Clinic College of Medicine, Rochester, Minnesota, U.S.A.; Honorio Delgado Chair, Universidad Peruana Cayetano Heredia, Lima, Perú

Correspondence: Alarcon.Renato@mayo.edu
} 


\section{Introduction}

Medical practice nowadays is a rather complex process in which numerous languages (technological, scientific, humanistic, philosophical, historical and ethical, among others) are spoken or written in the name of patient care, good health and its inherent quality of life component(1). Furthermore, the conceptual evolution of the field has seen the multiplication of terms, the accentuation of dichotomies and the inter-connection of areas of knowledge and research $(2,3)$ that, ultimately, cannot avoid a political impact and the convergence of those avenues into the field of Public Health and its many branches. In turn, the international scenario of practice, enhanced by the multifaceted phenomenon we call Globalization(4-6) has contributed to the coinage of terms such as Global Health $(\mathrm{GH})$, defined as the area of study, research and practice that places a priority on improving health services and achieving equity in health for all people worldwi$\mathrm{de}(7)$. Born in the 1970's(8), GH aspired to be, from the beginning, not only a body of policies or a bureaucratic echo chamber: it attempted to become a "movement of ideas" beyond mere statistics and graphs, engendering specific actions to be materialized by international agencies or foundations $(9,10)$ if and when not by selfish financial or commercial interests behind and within the socalled developed world(11).

One of the products of this movement was the emergence of specific foci of concern related to different areas of health and health care. Global Mental Health (GMH) was one of them, first saluted in the printed world by publications in the British Journal of Psychiatry (12,13) and, in the international field of health politics, by the World Health Organization's (WHO) Alma Ata Declaration on Primary Care(14). This was followed over the years by other respectable institutions such as the World Bank(15) and the Office of the U.S. Surgeon General(16). Defined as the subdiscipline of $\mathrm{GH}$ aimed at the implementation of evidence-based interventions for mental illness, GMH attempts to optimize the acceptability and feasibility of such interventions by enhancing their effectiveness and responding accurately to contextual socio-cultural factors(17). WHO's Report on the Global Burden of Disease (GBD)(18) put mental illness in the forefront of World health concerns and, in the $21^{\text {st }}$. Century, The Lancet Series, published between 2007 and 2013(19,20), provided it with a much needed scientific and academic blessing. Furthermore, the characterization of principles and actions linked to the socalled social determinants of mental health(21) has contributed to the universal acceptance of the term and its many implications.

There is also universal agreement in that good health care cannot take place without a well conceived and arrived at diagnosis of the conditions to be treated. Yet, psychiatric diagnosis is one of the most debated, controversial and complicated topics in contemporary Medicine (22,23). The problems are far from being solved in spite of recent and current work led by organizations such as the American Psychiatric Association (APA) with the fifth version of its Diagnostic and Statistical Manual of Mental Disorders (DSM-5)(24), WHO and its arduous work toward the $11^{\text {th }}$. Edition of its International Classification of Diseases (ICD-11)(25), and the U.S. National Institute of Mental Health (NIMH) pushing Research Domain Criteria (RDoC) (26) as the newest challenge from the neurobiological headquarters. This conflictive picture, however, only enhances the importance of diagnosis in the global perception of mental health.

For the purposes of this article, the two central concepts discussed above will require a bridging perspective of both theoretical and practical relevance, reason for which such two-faceted perspective is called clinical-cultural. In fact, psychiatric practice and its professionals know the unavoidable character of this dual approach even if they deny its inherent dichotomy. The clinical component of this combined perspective may be strictly based on the classic "doctor-patient relationship", sits on a conventional diagnostic process, uses the habitual clinical settings and, in spite of some neurobiological emphasis (or perhaps because of it), reinforces the connection between Psychiatry and the rest of Medicine $(27,28)$. The socio-cultural component is broader in its vision but more specific on its consideration of the socalled environmental factors playing a role in the symptoms and the suffering of the identified patient(29); the presence and impact of cultural 
factors and variables become irrefutable(30), the actual experience, perception and explanations of what is going on (31) and the individual, familybased and collective attitudes toward mental illness and the mentally ill(32) add unique features to the diagnostic task.

The review that follows will examine GMH and psychiatric diagnosis in some detail, focusing on recent findings that support or criticize each and both of them. A broad spectrum of issues within different areas of knowledge (resources, the mental disorder experience, diagnostic systems and professional and social attitudes toward the mentally ill) will be examined from the clinical and cultural perspectives.

Figure 1 represents contemporary medical (or psychiatric) practice as application of fundamental principles of GMH, first and foremost linked to diagnostic systems and perceived (also interactively) from cultural and clinical perspectives, supposedly integrated in the interviewing procedures $(1,33)$. The "external" links (SMG-Cultural perspective, and Diagnostic Systems-Clinical perspective) are definitely easier to see or conceive than the "internal" ones; actually, the latter entail both theoretical and practical difficulties: the clinical tools may still be insufficient to cover the many facets of GMH, and the cultural resources used today may not necessarily round up a truly complete diagnosis (34).

\section{Global Mental Health}

As mentioned above, GMH was incorporated by WHO as a central element of its mental health pronouncements and strategies, the 1978 Alma Ata Conference and its slogan "Health for all in the Year 2000" being an eloquent early example(14). The publication of the report on the Global Burden of Disease with the noted impact of six mental disorders among the first 20, in terms of Disability-associated Life Years (DALYs) $(18,19)$, and the substantial differences between developed and Low and Middle Income countries (LMICs) in prevalence and incidence of and service for mental, addiction-related and neurological disorders (35) have been hallmarks of the development of this field.

The main characteristics of GMH are its panoramic view of the state of affairs in the field, its strong epidemiological basis and the systematic use of an explicit and implicit comparative approach of the realities found in different settings of psychiatric care, mental health services and public health agencies(36). In the practice domain, some research areas have led to social or community-oriented interventions in the most prevalent disorders through the strong support and dissemination of Integrated Care (IC) concepts and strategies $(37,38)$. In a broader context, studies on the phenomena of migrations, violence, and inequities of care, and on the fate of minority and

Fig. 1. Fundamental Perspectives of the Practice of Medicine and its essential components.

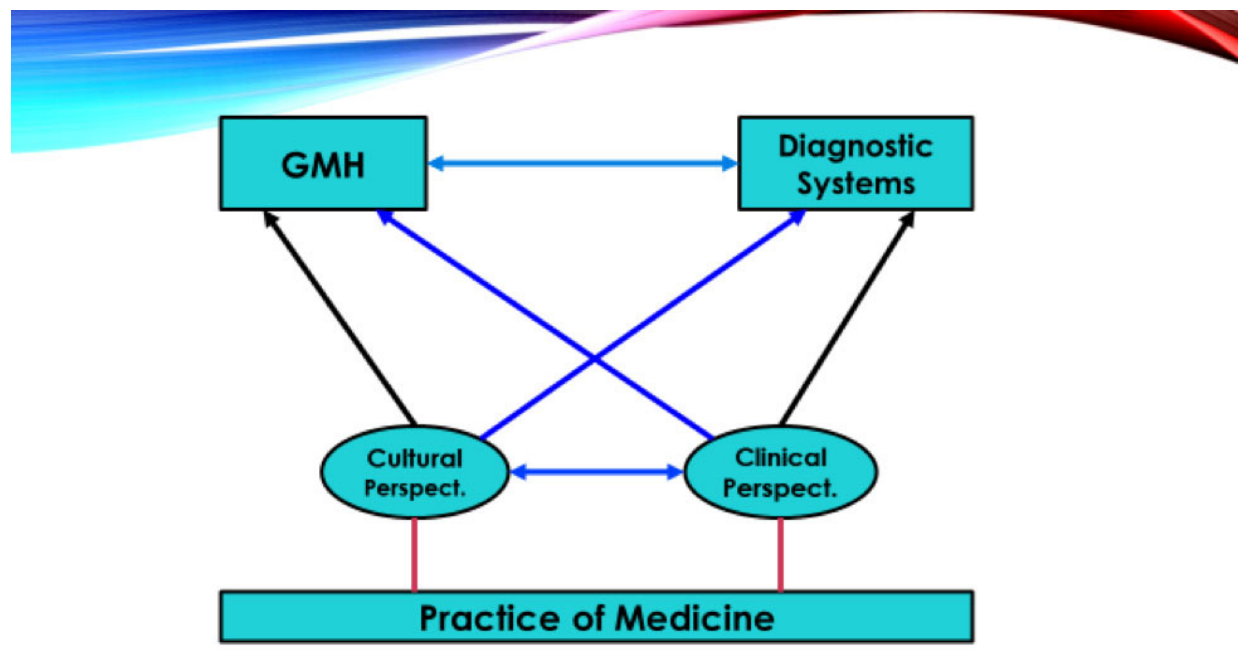


ethnic populations have produced significant re$\operatorname{sults}(39,40)$.

There seem to be no doubts about the great impact and significance of The Lancet Series on Global Mental Health, with three substantially documented contributions in 2007(19), 2011 and 2013(20). The most recent publication includes estimations of 306 diseases and injuries, and 2,337 consequences (by country, year, age and gender) in 188 countries, from 35,620 information sources sought between 1990 and 2013, with calculations of representativeness and severity distinctions coming from different causes. It is, indeed, a quite thorough testimony of crucial realities of health and mental health in today's world(18).

Not for being expected, most of the findings included in the Series lose significancy. Only a small fraction of individuals did not present sequelae of their main diagnoses; while acute consequences were mostly due to infectious diseases or shortterm injuries, the chronic ones were related to non-contagious diseases and "tension headaches". The latter could be considered an early parameter of an LYD and DALY increase (from 21.1 to 31.2 $\%$ ), with more than 200 million people affected by back pain and Major Depressive Disorder. Gains in age and life expectancy resulted in an increase of prevalence of diseases and consequences, besides that of comorbidities $(18,41,42)$. Literature reports on the reciprocal clinical interactions between mental disorders and chronic medical illnesses such as hypertension, diabetes, arthritis, cancer, bone marrow or immunological diseases have multiplied in the last decade $(18,43)$.

The global burden of mental, neurological and substance use-related disorders increased by $41 \%$ between 1990 and 2010, a very high proportion, even more dramatic as it does not take into account figures of excessive mortality or a variety of socio-economic consequences(44). To this, the fact that less than $1 \%$ of public budgets in LMICs are devoted to assistance and development of mental health (and neurological) services, adds ingredients of confusion and despondency. Worse yet, such funds are destined mostly to the small percent of chronic, long-term hospitalized mental patients than to acute cases or the growing youn- ger populations, much less to the implementation of mental health prevention programs(45). The global panorama of mental health is not too encouraging.

The above generates criticisms that go all the way to an analysis of "globalization and its discontents", to paraphrase Freud's famous book title(46). Described by many as a unique opportunity for economic growth, massive dissemination of information, true universalization and genuine source of collective hopes $(47,48)$, globalization has also been labeled as a sophisticated smuggling of neo-colonialist ideas, ergo a renewed version of political and economic dominance; it is also considered a pervasive conveyor of stereotypes and a messenger of inequities and cynical social stratifications (49,50). Similar ambivalence emerges in the judgment of the other driving force behind globalization: technology. To a due recognition of spectacular advances that have led to a variety of GMH-related accomplishments in recent years (e.g., planning and evaluation of services, integration of primary care, $\mathrm{MH}$ care, traditional and complementary medicine, use of tele-psychiatry and resource-mapping, and preservation of the "social capital")(51-55), statements of skepticism, distrust and controversy have also been made(56).

\section{Diagnostic systems}

The classic definition of diagnosis, based on strong etymological roots has changed in the last four decades, even though the parameters of symptomatic/syndromic nature, and the delineation of treatment assessment and choice, clinical course and outcome still remain $(22,26)$. To complicate matters, diagnosis is looked at from two different psychiatric practice perspectives: the purely clinical and the socio-cultural(57). The former, traditionally framed by the doctor-patient relationship(58) and established in habitual settings (outpatient, inpatient, emergency room, consultation-liaison, etc.) seems to be psychiatry's re-entry ticket into the field of conventional medicine, somewhat enhanced by a more than subtle neurobiological emphasis coming from today's clinical science and research. The result in the area of diagnosis is the search of one precise, expectedly well defined, categorical label calling for well-established, well spelled out management 
strategies. The reasoning behind this scheme is that if psychiatry is a branch of medicine, it is expected to act and do the way the rest of medicine does(59), technological progress included, with electronic documentation being its latest contribution(60); yet, the projections regarding the fate of the doctor-patient dyad seem to be quite negative: impersonalization or depersonalization (some call it robotization) of the relationship is already considered its worst outcome.

On its side, the socio-cultural perspective may be both, broader and more specific. Broader because it encompasses a multitude of variables giving shape to identity, social habits, religious beliefs, help-seeking patterns and what many people from many quarters call "environment"(61); and it is more specific because, by precisely defining those variables, it is also characterizing different sets or groups of people on the basis of geographic, ethnic, religious and epigenetic considerations(62). How the patient and their relatives perceive or explain disease and disease-induced suffering, and how their beliefs generate attitudes of empathy or disdain, of compassion or fear are distinctive socio-cultural features of any diagnosis(63). In short, the clinical perspective tends to find the similarities of homogeneity whereas the socio-cultural perspective accentuates the many shades of heterogeneity.

For decades, the two dominant diagnostic systems in psychiatry have been the American Psychiatric Association's DSM(24) and the WHO's $\operatorname{ICD}(25)$, both comfortably resisting the periodic appearances of national or regional glossaries or manuals that attempt to "glocalize" diagnostic practices in specific geographic settings(64). How do the two dominant systems relate to the nature and expectations of GMH?. Both certainly show advantages and disadvantages, the latter being varied and powerful in aspects as dissimilar as logistics (number of entities, implementation difficulties, differential diagnoses problems, etc.), theoretical basis, politics ("Westernized" DSM5 , "bureaucratized" ICD-10) or uneven cultural components $(65,66)$.

Psychiatric diagnosis is also one of the most multi-faceted scenarios of epistemological dilemmas in our discipline. Doctrine-related wars reflect the Science-Humanism dilemma through the notions of a "deteriorated machine" (the brain) vs. the drama of "a suffering human being" (67). The theoretical models confront the neuroscientific focus of the very new Research Domain Criteria (RDoC) $(26,68)$ with the psycho-socio-anthropological approach of a renascent Narrative Medicine(69). Operationally, the narrow and concrete vision of every reductionism faces the broader pluralism and its risks of superficiality and repetitiveness $(70,71)$. In terms of structure, the categorical and dimensional styles advocate the "black or white, never gray" diagnostic consideration and the notions of syndrome or spectrum, respectively. And finally, DSM-5 and ICD-10/11 represent the undeniable geo-political realities of competitiveness and dominance-seeking of the most powerful country on earth and the worldwide rubric of an international public health agency $(71,72)$.

\section{Global Mental Health and clinical practice}

At this juncture, it can be concluded that the alignment of GMH and clinical practice (with diagnosis as its point of departure) is uncertain, given the almost unavoidable presence of reductionisms of different kinds. As a result of a "diplomatic" management of the above conflicts, mostly stereotyped, commonplace pronouncements may come up, exposing not only the limitations of the responsible organizations but, most importantly, accentuating differences and inequities in service, management and prevention of a multitude of mental disorders across the world. These differences, extended to education and research areas between countries, continents and regions, also constitute a strong call for changes or rectifications of course in mental health policies, strategies and specific actions at each and every level.

Nevertheless, it would be unfair not to acknowledge progress made in relevant areas of investigation along the same lines. Well-documented demands of efficiency, flexibility, practicality, clinical pertinence and cultural adaptability and applicability have been made regarding both DSM-5 and $\operatorname{ICD}(73,74)$. Clinical research with a GMH outreach include themes of integrated care, special populations, risk factors, comorbidities, sub-threshold disorders and "functional im- 
provement"(75-79). Epidemiological studies regarding NMS disorders and gap treatments(41), and innovative service provisions of cultural consultations in general hospital settings, cost effectiveness and the institutionalization of use of research findings(80-82) are outstanding contributions. The best examples of public healthmental health proper are the inquiries into disasters $(83)$ or about the troubles and tribulations of immigrant and refugee populations $(40,84-86)$. Psychiatric education research has benefited from the findings of robust competence-based efforts in different settings(87).

\section{The future}

Shaping the future of a psychiatric practice based on GMH principles and solid diagnostic grounds will, in turn, provide stronger clinical and sociocultural skills to all the actors. First of all, the implementation of an objective approach requires adequate policies and resources beginning with a genuine integration of the work of primary care providers and mental health professionals through the constitution of multidisciplinary, democratized teams open to the active participation of the patients themselves and their families $(31,75,88)$. All of this entails respect for the human dignity and the cultural background of the individual patient and his/her surroundings, making it possible a comprehensive, realistic and pragmatic clinical management and reasonable outcome-oriented follow up $(63,70,89)$.

Preventive measures mainly aimed at alleviating social and economic consequences of mental health problems complement the traditional goals of reduction in morbidity and mortality. In such context, the future of services provision would require the use of three types of platforms as suggested by Patel et al.(45). The first, at the general population level, must be mostly based on legislative measures of, for instance, restriction of the access to self-harm or suicide tools or weapons, and reduction of availability and access to alcohol and drugs. The second, at the community level, would include programs such as parental education or high school-based training on vital skills to reinforce social and emotional competencies. The third, at the health care level as such, can work through three equally innovative channels: self-management of emotional problems, primary care and community outreach, and hospital care proper. Arriving at universal health coverage $(77,90)$ becomes a much hoped for objective of this justifiably ambitious agenda.

Two other substantial components of this future are the management of socio-cultural aspects of mental health care and a much needed approach between GMH and neurosciences $(56,70,76,91)$. Both can only materialize on the basis of cogently conceived international, cooperative research programs(92). The socio-cultural focus can be based, to begin with, on the recent contributions to the DSM-5: the systematic use of the Cultural Formulation Interview(63), the exploration of cultural concepts of distress $(24,93,94)$, and appropriate use of cultural psychotherapies and traditional healers(95). All these keeps alive the need of continuous cultural negotiations of any kind of clinical encounter across the world.

The connection between GMH and neurosciences is another reality in today's health stage. Stein et al. $(56,91)$ examine the advances of the so-called translational neuroscience in pursuit of a better understanding of the role of neural circuits, neuro-imaging, genetic and molecular basis in mental disorders, but also the contrasts between it and GMH. Their analysis end with an optimistic estimation of the synergistic potential of the two fields, their probabilities of integration, perhaps through what is now called epigenetics $(62,96)$. Maximizing the opportunities of a genetic-environmental linkage would, in turn, contribute to an improvement of diagnosis and treatment of mental disorders without the negative implications of depersonalization and dehumanization.

\section{Conclusions}

Global Mental Health can be conceived as the complex but ultimately harmonious and solid outcome of a variety of interactive processes that include a rational practice based on a cogent diagnostic approach nourished by clinical and sociocultural inputs. Fig. 2 attempts to graphically represent these transactions as a sum of concentric, logistically integrated perspectives. They go from the most intimate central circle (individual pers- 
pective) to the fully integrated clinical-cultural perspective through the socio-cultural (environmental) vantage point and the clinical-diagnostic steps. A structurally solid and sustained process that addresses individuals as such and individuals as group or community members, expecting always an adequate support and feedback from a mature society, can then only aspire to an objective, balanced and genuinely human GMH, essential component of a sound global health.

Reaching these goals can only result from a duly planned process, executed with adequate resources (human and otherwise), efficiency and compassion. However, even the total availability of these ingredients will not be sufficient without an adequate public health/mental health basic and clinical research oriented to a comprehensive assessment of health and GMH(97). National research plans must be linked to international collaborative research programs, particularly among Latin American countries in a concerted effort to end a regrettably prolonged absence from the world scene(98). Research topics of common interest and transcendence must be carefully examined and orderly added to the exchange of actual works, interactions of experienced researchers, training of young ones, development of new, original themes, consistent worldwide publications and progressive educational and training programs.

Fig 2. Global Mental Health as a result of the integration of perspectives.

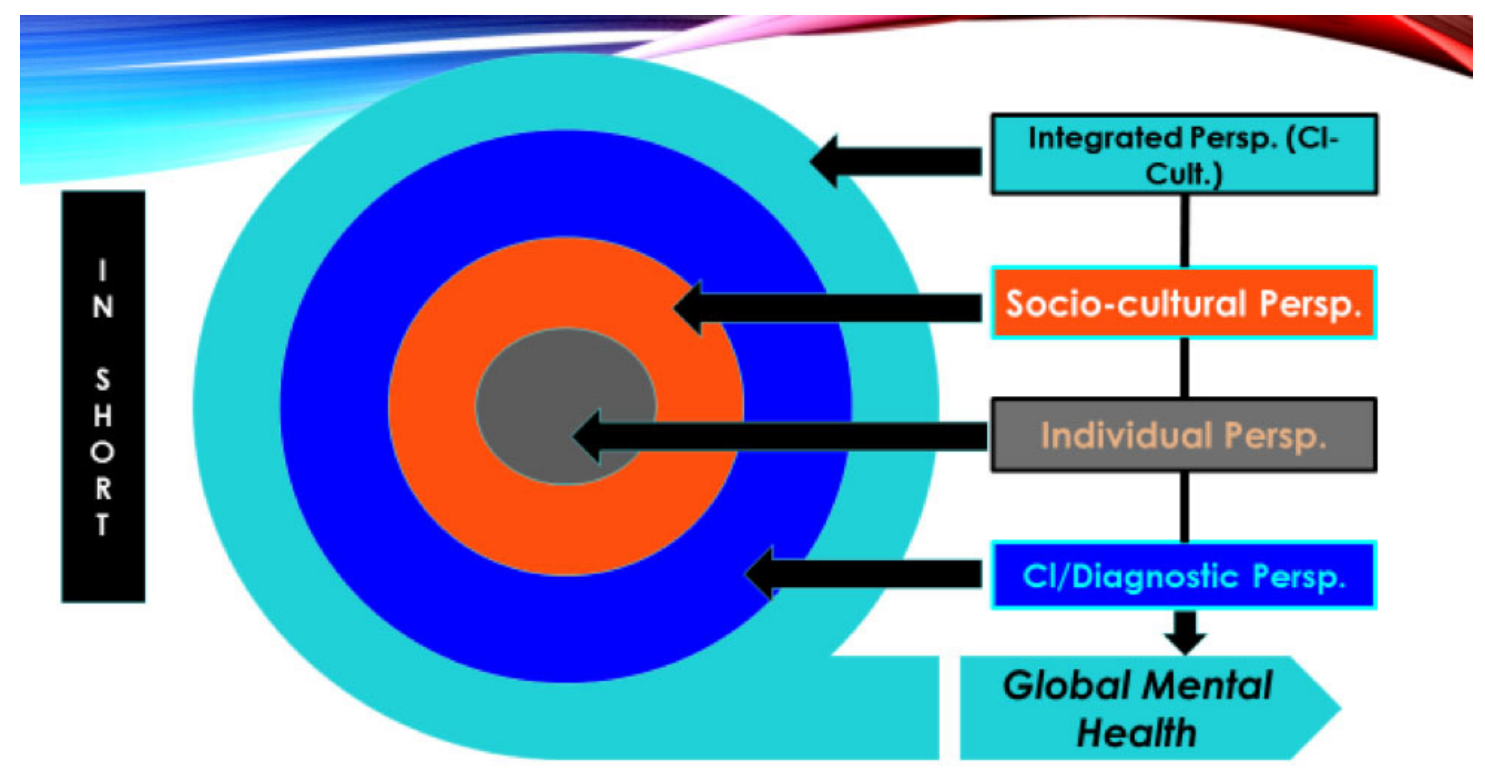


Global Mental Health and systems of diagnostic classification: clinical and cultural perspectives - Renato D. Alarcón

\section{References}

1. Zuger A. Talking to patients in the $21^{\text {st }}$. Century. JAMA, 2013; 309 (24): 2384-2385.

2. Tretter F, Gebicke-Haerter PJ. Philosophy of neuroscience and options of systems science. Pharmacopsychiatry 2009; 42 (Suppl. 1), S2-S10. doi: 10.1055/s-0029-1215598.

3. Kirmayer LJ, Crafa D. What kind of science for psychiatry? Front Hum Neurosci 2014; 8: 435-450.

4. Desjarlais R, Eisenberg L, Good B, Kleinman A. (Eds.) World Mental Health: Problems and priorities in Low-Income countries. Oxford, UK: Oxford University Press; 1995.

5. Feachem RG. Globalisation is good for your health, mostly. Br Med J 2001; 323: 504-506.

6. Bauman Z. Globalisation: The Human Consequences. Cambridge, UK: Polity Press; 1998.

7. Koplan JP, Bond TC, Merson MH, Reddy KS, Rodriguez MH, Sewankambo NK et al. Towards a common definition of Global Health. Lancet 2009; 373: 1993-1995.

8. Macfarlane SB, Jacobs M, Kaaya EE. In the name of global health: Trends in academic institutions. $J$ Public Health Policy 2008; 29: 383-401.

9. Mitchell SD. Unsimple Truths: Science, Complexity and Policy. Chicago, Il.; University of Chicago Press.

10. World Health Organization Report. Mental Health: New Understandings. New Hope. Geneva; 2001.

11. Marsella AJ. "Hegemonic" globalization and Cultural Diversity: The risks of Monoculturalism. Austr Mosaic 2005; 11: 15-19.

12. Leff JP. Transcultural influences on psychiatrists' rating of verbally expressed emotion. Brit J Psychiatry 1974; 125: 336340.

13. Fernando SJM. A cross-cultural study of some familial and social factors in depressive illness. Brit J Psychiatry 1975; 127: 46-53.

14. World Health Organization. Declaration of Alma Ata, International Conference on Primary Health Care. Almaty, Kazakhstan, Sept. 6-12, 1978.

15. The World Bank. Out of the Shadows. Making Mental Health a Global Development Priority. World Bank Group/IMF Spring Meeting, April 2016.

16. U. S. Department of Health and Human Services. Mental Health: Culture, Race and Ethnicity. A supplement to Mental Health: A Report of the Surgeon General. Rockville, MD: US Department of Health and Human Services, Substance Abuse and Mental Health Services Administration, Center for Mental Health Services, 2001.

17. Kohrt BA, Mendenhall E. Global Mental Health. Anthropological Perspectives. Walnut Creek, CA: Left Coast Press; 2015.

18. Murray CJ, Barber RM, Foreman KJ, et al. Global, regional and national disability-adjusted life years for 306 diseases and injuries and healthy life expectancy for 188 countries, 1990-2013: quantifying the epidemiological transition. Lancet 2015; 386: 2145-2191.

19. Patel V, Garrison P, Marti JJ, Minas H, Prince M, Saxena S. The Lancet's Serie on Global Mental Health: 1 year on. Lancet 2008; 372: 1354-1357.

20. Stephan KE, Binder EB, Breakspear M, Dayan P, et al. Charting the landscape pf priority problems in psychiatry, part 2: pathogenesis and etiology. Lancet 2016; 3: 84-90.

21. Allen J, Balfour R, Bell R, Marmot M., Social determinants of mental health. Int Rev Psychiatry 2014; 26: 392-407.

22. Kupfer DJ, First MB, Regier DA. (Eds.) A Research Agenda for DSM-5. Washington DC: American Psychiatric Publishing; 2002.

23. Hyman SE. Can neuroscience be integrated into the DSM-V? Nat Rev Neurosci 2007; 8: 725-732.

24. American Psychiatric Association. Diagnostic and Statistical Manual of Mental Disorders, $5^{\text {th }}$. Edition (DSM-5). Arlington, VA: American Psychiatric Publishing; 2013.

25. World Health Organization. International Classification of Diseases, $10^{\text {th }}$ edition (ICD-10), Section VI, Mental Disorders. Geneva: 1998.

26. Insel T, Cuthbert B, Garvey M, et al. Research Domain Criteria (RDoC): toward a new classification framework for research in mental disorders. Am J Psychiatry 2010; 167: 748-751.

27. Verhulst J, Kramer D, Swann AC, et al. The medical alliance: from placebo response to alliance effect. J Nerv Ment Dis 2013; 201: 546-552.

28. Rojas-Malpica C. Definición, contenido y límites de la psiquiatría contemporánea. Salud Mental 2012; 35: 181-188.

29. Curley JP, Jensen CL, Mashoodh R, Champagne FA. Social influences on neurobiology and behavior: epigenetic effects during development. Psychoneuroendocrinology 2011; 36: 352-371. 
30. Alarcón RD. Cultural Psychiatry: A general perspective. In: Alarcón RD. (Ed.) Cultural Psychiatry. Basel: Karger; 2013: $1-14$.

31. Kirmayer LJ, Bhugra D. Culture and mental illness: social context and explanatory models. In: Salloum IM, Mezzich JE (eds.) Psychiatric Diagnosis: Patterns and prospects. New York: John Wiley \& Sons; 2009: 29-37.

32. Dietrick S, Beck M, Bujantugs B, Kenzine D, Matschinger H, Angermeyer MC. The relationship between causal beliefs and social distance toward mentally ill people. Austr NZ J Psychiatry 2004; 38: 348-354.

33. Tasman A, Kay J, Ursano R. The Psychiatric Interview. Chichester, UK: Johns Wiley \& Sons; 2013.

34. Alarcón RD. Les composantes culturelles dans le DSM-5: contenus fondamentaux ou concessions purement cosmétiques? L'Evol Psychiatrique 2014; 79: 39-53.

35. Patel V, Araya R, Chatterjee $\mathrm{S}$, et al. Treatment and prevention of mental disorders in low-income and middle-income countries. Lancet 2007; 370: 991-1005.

36. Patel V, Prince M. Global Mental Health: a new global health field comes of age. JAMA 2010; 303: 1976-1977.

37. Collins PY, Patel V, Joestl SS, March D, Insel TR, Daar AS, et al. Grand challenges in global mental health. Nature 2011; 475: 27-30.

38. Walker ER, McGee RE, Druss BG. Mortality in mental disorders and global disease burden implications: a systematic review and meta-analysis. JAMA Psychiatry 2015; 72: 334-341. doi: 10.1001/jamapsychiatry.2014.2502.

39. Claro HG, Oliveira MA, Bourdreaux BT, Fernandes IF, Pinho PH, Tarifa RR. Drug use, mental health and problems related to crime and violence: cross sectional study. Rev Lat Am Enfermagem 2015; 23: 1173-1180.

40. Betancourt TS, Frounfelker R, Mishra T, Hussein A, Falzarano R. Addressing health disparities in the mental health of refugee children and adolescents through community-based participatory research: a study in two communities. Am J Public Health 2015; 105 (Suppl. 3): S475-S482. doi: 10.2105/AJPH.2014.302504.

41. Collins PY, Musisi S, Frehywot S, Patel V. The core competencies for mental, neurological and substance use disorder care in sub-Saharan Africa. Glob Health Action 2015; 8: 266-282.

42. Scott KM, Von Korff M, Alonso J, Angermeyer MC, et al. Mental-physical co-morbidity and its relationship with disability: Results from the World Mental Health Surveys. Psychol Med 2009; 39: 33-43.

43. Ormel J, Petukhova M, Chatterji S, Aguilar-Gaxiola S, et al. Disability and treatment of specific mental and physical disorders across the world. Br J Psychiatry 2008; 192: 368-375.

44. Vos T, Barber RM, Bell B, Bertozzi-Villa A, Biryukov S, et al. Global, regional and nacional incidence, prevalence and years lived with disability for 301 acute and chronic diseases and injuries in 188 countries, 1990-2013: a systematic analysis for the Global Burden of Disease Study 2013. Lancet 2015; 386: 743-800. doi: 10.101016/So140-6736(15) 60692-4

45. Patel V, Chisholm D, Parikh R, et al. Addressing the burden of mental, neurological and substance use disorders: key messages from Disease Control Priorities, $3^{\text {rd }}$. edition. Lancet 2015, 2015. pii: S0140-6736 (15)00390-6.

46. Freud S. Civilization and its Discontents. New York: Norton; 1962.

47. Stiglitz J. Globalization and its Discontents. London: Penguin Books; 2002.

48. Atasoy Y. Explaining Globalization. In: Atasoy Y, Carroll V. (Eds.) Global shaping and its alternatives. Bloomfield: Kumarian Press; 2003.

49. Alegría M, Atkins M, Farmer E, Slaton E, Stelk W. One size does not fit all: taking diversity, culture and context seriously. Admin Policy Ment Health 2010; 37: 48-60.

50. Demmytenaere K, Brufaerts R, Posada-Villa J, Gasquet I, et al. Prevalence, severity and unmet needs for treatment of mental disorders in the World Health Organization World Mental Health Surveys. JAMA 2004; 291: 2581-2590.

51. Breuer E, De Silva MJ, Shidaye R, Petersen I, Nakku J, et al. Planning and evaluating mental health services in low- and middle-income countries using Theory of Change. Brit J Psychiatry 2015 Oct 7. pii: bjp.bp.114.153841.

52. Gureje O, Nortje G, Makanjuola V, et al. The role of global traditional and complementary systems of medicine in the treatment of mental health disorders. Lancet Psychiatry 2015; 2: 167-177.

53. Ae-Ngibise KA, Doku VC, Asante KP, Owusu-Agyei S. The experience of caregivers of people living with serious mental disorder: a study from rural Ghana. Glob Health Action 2015; 8: 26957. doi: 10.3402/gha/v8.26957.

54. Ehsan AM, De Silva MJ. Social capital and common mental disorder: a systematic review. J Epidemiol Community Health 2015; 69: 1021-1028. doi:10.1136/jech-2015-205868.

55. Augusterfer EF, Mollica RF, Lavelle J. A review of telemental health in international and post-disaster settings. Int Rev Psychiatry 2015; 27: 540-546.

56. Stein DJ, Illes J. Beyond Scientism and Skepticism: An Integrative Approach to Global Mental Health. Front Psychiatry 2015; 6: 166-172. doi: 10.3389/fpsyt.2015.00166.

57. Alarcón RD. Culture, cultural factors and psychiatric diagnosis: review and projections. World Psychiat 2009; 8: 1-9. 
Global Mental Health and systems of diagnostic classification: clinical and cultural perspectives - Renato D. Alarcón

58. Ursano AM, Sonnenberg SM, Ursano RJ. Physician-Patient Relationship. In: Tasman A, Jay J, Lieberman JA, First MB, Riba MB. (Eds.) Psychiatry, 4 ${ }^{\text {th }}$ Ed., Vol 1. West Sussex, UK: Wiley \& Sons; 2015: 21-33.

59. Guze SB. Why Psychiatry is a branch of Medicine. New York: Oxford University Press; 1992.

60. Turkle S. Alone Together: Why we expect more from Technology and less from each other. New York: Basic Books; 2011.

61. Group for the Advancement of Psychiatry, Committee on Cultural Psychiatry. Cultural Assessment in Clinical Psychiatry. Washington DC: American Psychiatric Publishing; 2002.

62. Champagne FA. Epigenetic influence of social experiences across the lifespan. Dev Psychobiol 2010; 52: 1-13.

63. Lewis-Fernández R, Aggarwal NK. Culture and Psychiatric Diagnosis. In: Alarcon RD. (Ed.) Cultural Psychiatry. Basel: Karger; 2013: 15-30.

64. Asociación Psiquiátrica de América Latina, Sección de Diagnóstico y Clasificación. Guía Latinoamericana de Diagnóstico Psiquiátrico. Versión Revisada. Lima, Perú: Instituto Nacional de Salud Mental "Honorio Delgado-Hideyo Noguchi”; 2012.

65. Mellsop G, Banzato C, Shinfuku N. An international study of the views of psychiatrists on present and preferred characteristics of classifications of psychiatric disorders. Int J Mentl Health 2008; 36: 18-26.

66. Reed GM, Mendonca Correia J, Esparza P, Saxena S, Maj M. The WPA-WHO Global Survey of psychiatrists' attitudes towards Mental Disorders Classifications. World Psychiatry 2011; 10: 118-131.

67. Alarcón RD. Science and Humanism in Contemporary American Psychiatry: Dialogues toward a desirable convergence. George Tarjan Lecture, American Psychiatric Association Annual Meeting. Honolulu, Hawaii, May 20, 2011.

68. Cuthbert BN. The RDoC framework: facilitating transition from ICD/DSM to dimensional approaches that integrate neuroscience and psychopathology. World Psychiatry 2014; 13: 28-35. doi: 10.1002/wps.20087.

69. Lewis B. Narrative Psychiatry: How stories can shape clinical practice. Baltimore: Johns Hopkins University Press; 2011.

70. Kirmayer LJ, Gold I. Re-socializing psychiatry: critical neuroscience and the limits of reductionism. In: Choudhury S, Slaby J. (Eds.) Critical Neuroscience: A Handbook of the Social and Cultural contexts of Neuroscience, Oxford, UK: Blackwell; 2012.

71. International Advisory Group for the Revision of ICD-10 Mental and Behavioural Disorders. A conceptual framework for the revision of the ICD-10. Classification of Mental and Behavioural Disorders. World Psychiatry 2011; 10: 86-92.

72. Regier DA, Narrow WE, Kuhl EA. The conceptual development of DSM-V. Am J Psychiatry 2009; 166: 645-650.

73. Zielasek J, Freyberger HJ, Janner M. Assessing the opinions and experiences of German-speaking psychiatrists regarding necessary changes for the $11^{\text {th }}$. Revision of the Mental Disorders Chapter of the International Classification of Diseases (ICD-11). Eur Psychiatry 2010; 25: 437-442.

74. Suzuki Y, Takahashi T, Nagamine M. Comparison of psychiatrists' views on classification of mental disorders in four East Asian countries area. Asian J Psychiatry 2010; 3: 20-15.

75. Briot P, Brechat PH, Reiss-Brennan B, Cannon W, Brechat N, Teil A. Integrated care delivery system for mental illness: A case study of Intermountain Healthcare (USA). Sante Publique 2015; 27 (Suppl. 1): S199-S208.

76. Ordoñez AE, Collins PY. Advancing Research to Action in Global Child Mental Health. Child Adolesc Psychiatr Clin N Am 2015; 234: 679-697. doi: 10.1016/j.chc.2015.06.002.

77. McCall RB, Groark CJ, Rygaard NP. Global research, practice and policy issues on the care of infants and young children at risk: the articles in context. Infant Ment Health J 2014; 35: 87-93. doi: 10.1002.imhj.21441.

78. Moore SE, Scott JG, Ferrari AJ, Mills R, et al. Burden attributable to child maltreatment in Australia. Child Abuse Negl 2015; 48: 208-220. doi: 10.1016/j.chiabu.2015.05.006.

79. Amerio A, Stubbs B, Odone A, Tonna M, et al. The prevalence and predictors of comorbid bipolar disorder and obsessive-compulsive disorder: A systematic review and meta-analysis. J Affect Disord 2015; 186: 99-109.

80. Kirmayer LJ, Guzder J, Rosseau C. (Eds.) Cultural Consultation: Encountering the Other in Mental Health Care. New York: Springer; 2014.

81. Scarpinati Rosso M, Baärnhielm S. Use of the Cultural Formulation in Stockholm: a qualitative study of mental illness experience among migrants. Transcult Psychiatry 2012; 49: 283-301.

82. Bhui KS, Owiti JA, Palinski A, Ascoli M, De Jongh B, et al. A cultural consultation service in East London: experiences and outcomes from implementation of an innovative service. Int Rev Psychiatry 2015; 27: 11-22.

83. Satcher D, Friel S, Bell R, et al. Natural and manmade disasters and mental health. JAMA 2007; 298: 2540-2542.

84. Butler M, Warfa N, Khatib Y, Bhui K. Migration and common mental disorder: an improvement in mental health over time? Int Rev Psychiatry 2015; 27: 51-63.

85. World Association of Cultural Psychiatry. Position Statement on the Migrant Crises around the World. $4^{\text {th }}$. World Congress of Cultural Psychiatry, Puerto Vallarta, México, Oct. 29-Nov. 2, 2015. 
86. Budwani H, Hearld KR, Chavez-Yenter D. Generalized Anxiety Disorder in racial and ethnic minorities: a case of nativity and contextual factors. J Affect Disord 2015; 175: 275-280. doi: 10.1016/j.jad.2015.01.035.

87. Heffernan E, Andersen K, Kinner SA. Enhancing research quality through cultural competence: a case study in Queensland prisons. Australas Psychiatry 2015; 23: 654-657.

88. Scorza P, Masyn KE, Salomon JA, Betancourt TS. A latent transition analysis for the assessment of structured diagnostic interviews. Psychol Assess 2015; 27: 975-984.

89. Lund C, Alem A, Schneider M, Hanlon C, Ahrens J, et al. Generating evidence to narrow the treatment gap for mental disorders in sub-Saharan Africa: rationale, overview and methods of AFFIRM. Epidemiol Psychiatr Sci 2015; 24: 233240.

90. United Nations General Assembly, 67 ${ }^{\text {th }}$. Session. Global Coalition for Universal Health Coverage. Resolution on Global Health and Foreign Policy. Adopted on Dec. 12, 2012.

91. Stein DJ, He Y, Phillips A, Sahakian BJ, Williams J, Patel V. Global Mental Health and Neurosciences: potential synergies. Lancet Psychiatry 2015; 2: 178-185.

92. Bridges AJ, Gregus SJ, Rodriguez JH, Andrews AR, Villalobos BT, Pastrana FA, Cavell TA. Diagnoses, intervention strategies and rates of functional improvement in integrated behavioral health care patients. J Consult Clin Psychol 2015; 83: 590-601. doi: 10.1037/a0038941

93. Lewis-Fernández R, Aggarwal NK, Baarnhielm S, Rohlof H, Kirmayer LJ, Weiss MG, et al. Culture and psychiatric evaluation: operationalizing cultural formulation for DSM-5. Psychiatry 2014; 77: 130-154.

94. Hinton DE, Lewis-Fernández R. Idioms of distress among trauma survivors: subtypes and clinical utility. Cult Med Psychiatry 2010; 34: 209-218.

95. Tseng W-S, Stretzler J. (Eds.) Culture and Psychotherapy: A Guide to Clinical Practice. Washington DC: American Psychiatric Publishing; 2008.

96. Zhang TY, Meaney MJ. Epigenetics and the environmental regulation of the genome and its function. Annu Rev Psychol 2010; 61: 439-466.

97. Sweetland AC, Oquendo MA, Carlson C, Magidson JF, Wainberg ML. Mental health research in the global era: Training the next generation. Acad Psychiatry 2015; 39: 1-6.

98. Alarcón RD. El precio de la ausencia: Visibilidad de la psiquiatría latinoamericana en el mundo. Salud Mental 2015; 38: $1-14$.

Received: January 29, 2016

Accepted: February 15, 2016 